\title{
Demonstration of the ability of the bacterial polysaccharide FucoPol to flocculate kaolin suspensions
}

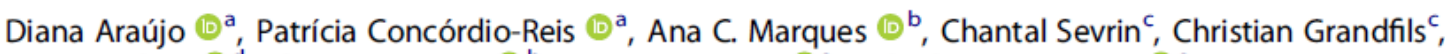 \\ Vítor D. Alves $\mathbb{C}^{\mathrm{d}}$, Elvira Fortunato $\mathbb{C}^{\mathrm{b}}$, Maria A. M. Reis $\mathbb{C}^{\mathrm{a}}$ and Filomena Freitas $\mathbb{C}^{\mathrm{a}}$ \\ aUCIBIO-REQUIMTE, Chemistry Department, Faculty of Sciences and Technology, Universidade NOVA de Lisboa, Caparica, Portugal; ${ }^{\mathrm{b}} \mathrm{i}$ N/ \\ CENIMAT, Department of Materials Science, Faculty of Sciences and Technology, Universidade NOVA de Lisboa and CEMOP/UNINOVA, Caparica, \\ Portugal; 'Interfaculty Research Centre of Biomaterials (CEIB), University of Liège, Liège, Belgium; 'LEAF - Linking Landscape, Environment, \\ Agriculture and Food, Instituto Superior de Agronomia, Universidade de Lisboa, Lisboa, Portugal
}

\begin{abstract}
In this study, the flocculation properties of FucoPol, a bacterial extracellular polysaccharide, were investigated. FucoPol is a high molecular weight polymer and negatively charged due to the presence of glucuronic acid and the acyl groups succinyl and pyruvyl. High flocculation rate values (>70\%) were achieved with a low bioflocculant dosage of $1 \mathrm{mg} / \mathrm{L}$, for $\mathrm{pH}$ values in the range $3-5$ and temperature within $15-20^{\circ} \mathrm{C}$. The bioflocculant was also shown to be stable after freezing/thawing and heating up to $100^{\circ} \mathrm{C}$. Given the polymer's anionic character, the size of flocs formed and their surface profile, bridging seems to be the main flocculation mechanism of FucoPol. This study demonstrated that FucoPol is a promising natural, biodegradable and biocompatible alternative to the currently used synthetic or inorganic hazardous products, with potential to be used as a novel flocculation agent in several applications, such as water treatment, food or mining. Further studies will involve evaluating the reduction of cation dosage on flocculation efficiency, as well as testing the applicability of FucoPol to flocculate different types of suspended solids, such as, for example, activated carbons, soil solids or yeast cells.
\end{abstract}

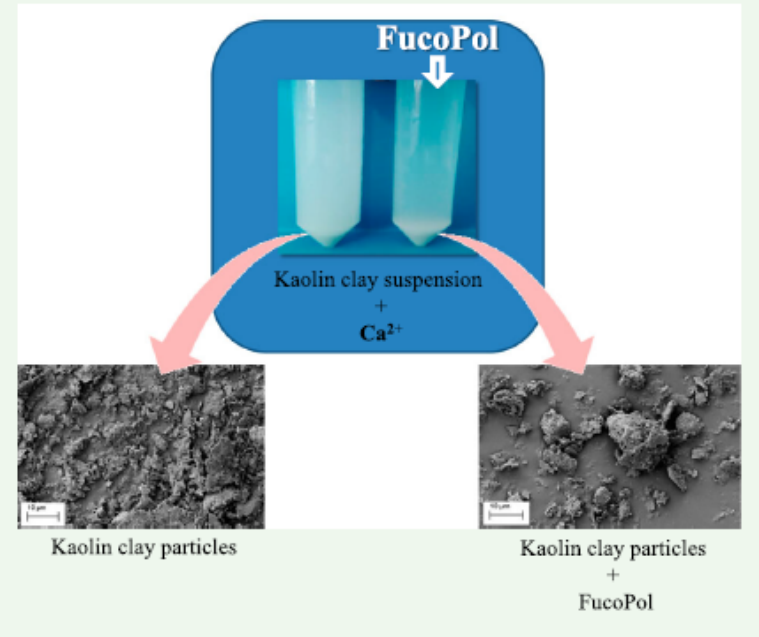

ARTICEE HISTORY Received 8 March 2018 Accepted 2 July 2018

\section{KEYWORDS}

Kaolin; flocculation;

Enterobacter A47;

exopolysaccharide; FucoPol

\section{Introduction}

Nowadays, flocculants are widely used in wastewater and drinking-water treatment, food and fermentation downstream processing, as well as in textile, pharmaceutical and cosmetic industries. They can be classified as inorganic flocculants (e.g. aluminum sulfate, polyaluminium chloride), organic synthetic flocculants (e.g. polyacrylamide derivatives, polyethylenimine) and bioflocculants (e.g. chitosan, sodium alginate, microbial flocculants) [1]. Synthetic and inorganic flocculants are the most commonly used, due to their lower costs and high efficiency [2]. However, some of them pose health and/or environmental problems. Most of them are not 
biodegradable. In the case of polyacrylamide-derived flocculants, for example, their acrylamide monomer is known to be highly toxic and carcinogenic [3]. Moreover, aluminum salts are known to cause Alzheimeŕs disease [4]. Bioflocculants are macromolecules obtained from natural sources which have the ability to flocculate particles (suspended solids, cells, colloidal solids) out of solution [2]. These flocculants are emerging as attractive alternatives to the traditional flocculants, thanks to their biodegradable and usually safe nature.

Over the past few decades, many microorganisms, such as bacteria, algae and fungi, have been reported to produce polymers presenting flocculating capacity [1]. These macromolecules include proteins, glycoproteins and polysaccharides. Microbial biopolymer flocculants have the advantage of being produced economically at large scale, under controlled environmental conditions, while being usually easily recovered from the fermentation broth. Hence, these bio-friendly compounds deserve more and more interest.

Two mechanisms were proposed to describe the aggregation of particles by biopolymer flocculants, namely, polymer bridging and charge neutralization, which depend on the physical and chemical characteristics of the flocculant agent [5]. When a neutral flocculant is adopted or when the flocculant has the same charge as the particles, the polymer's chains bring the particles closer together in order to form flocs. In this case, a cation is usually involved in view to reduce the effect of the charges and facilitates the adsorption of the particles by the bioflocculant. According to a charge neutralization mechanism, the biopolymer flocculant is expected to reduce the charge density of the particle surface and, with as end results, the formation of flocs by reduction of the coulombic repulsion forces between particles [5].

Microorganisms such as Rhodococcus erythropolis [6] and Bacillus subtilis [7] produce protein flocculants, whereas the bioflocculants produced by Bacillus licheniformis [8] and Halobacillus sp. [9] are composed of glycoproteins. However, the majority of bioflocculantproducing organisms, such as Bacillus sp., Aeromonas sp., Klebsiella sp. and Enterobacter sp., are known to produce polysaccharide flocculants $[1,10]$. Several bacteria of the Genus Enterobacter were reported to produce carbohydrate polymers with interesting flocculation rate. Yokoi et al. [11] reported the potential of a biopolymer produced by Enterobacter sp. BY-29 to flocculate, not only inorganic suspensions, such as kaolin and activated carbon, but also organic suspensions of cellulose and yeast. Lu et al. [12] reported that the polysaccharide produced by $E$. aerogenes $\mathrm{W}-23$ was able to flocculate a trona suspension with higher efficiency than conventional chemical flocculants. The extracellular polysaccharide synthesized by the bacterium Enterobacter A47, named FucoPol, was also reported to have flocculating capacity [13].

In this study, the flocculating capacity of FucoPol was assessed. Kaolin clay, a widely used model suspension to study the flocculation properties of flocculant materials, was used due to its stability and well defined surface properties, which lead to a better understanding of the flocculation process. The factors affecting the flocculating rate of the biopolymer (dosage, presence of different cations, dosage of cations, kaolin suspension concentration, $\mathrm{pH}$ and temperature) and the flocculation mechanism of FucoPol were investigated. Moreover, the cultivation broth, as well as the cell-free supernatant containing the biopolymer, were also tested for their flocculating activity.

\section{Materials and methods}

\subsection{Bioflocculant production and characterization}

The bacterium Enterobacter A47 was cultivated in a $2 \mathrm{~L}$ bioreactor (BioStat B-plus, Sartorius, Germany) using Medium $E^{*}$ supplemented with glycerol $(40 \mathrm{~g} / \mathrm{L})$ [14]. The bioreactor was operated as described by Torres et al. [15]. The bioflocculant, FucoPol, was extracted from the cultivation broth as described by Ferreira et al. [16]. The apparent viscosity of the broth was measured as described by Freitas et al. [13]. The purified bioflocculant was characterized in terms of sugar monomers and acyl groups composition, total inorganic and protein contents, average molecular weight and polydispersity index, as described by Torres et al. [15]. The chemical structure of purified bioflocculant FucoPol was assessed by Fourier transform infrared spectroscopy (FT-IR) (Nicolet 6700 FT-IR, Thermo Electron Corporation, Waltham, MC, USA) with a diamond crystal attenuated total reflectance (ATR) accessory, over a wavenumber range of $525-4500 \mathrm{~cm}^{-1}$.

\subsection{Flocculation rate tests}

The flocculation rate (FR) was measured using kaolin clay (Ref.60609, Sigma-Aldrich, Germany) as the test solids suspension. The zeta potential of kaolin clay suspension used in this study was $-24.8 \mathrm{mV}$. In brief, $4.9 \mathrm{~mL}$ of a $\mathrm{CaCl}_{2}$ aqueous solution ( $249 \mathrm{mmol} \mathrm{Ca}^{2+}$ per litre) and $0.1 \mathrm{~mL}$ of the flocculating agent in aqueous solution were added into $45 \mathrm{~mL}$ of kaolin suspension $(5 \mathrm{~g} / \mathrm{L}, \mathrm{w} / \mathrm{v})$ in Falcon ${ }^{\mathrm{TM}}$ conical tubes $(30 \times 115 \mathrm{~mm})$. The mixtures were vigorously shaken for $20 \mathrm{~s}$ and allowed to stand for $5 \mathrm{~min}$ at room 
temperature. Afterwards, one millilitre was removed from the upper layer of the suspension and the optical density was measured at $550 \mathrm{~nm}\left(O D_{550}\right)$. A blank sample was prepared by replacing the flocculating agent by the same volume of deionized water $\left(O D_{550}\right.$, blank). The FR (\%) was calculated according to the following equation:

$$
\mathrm{FR}(\%)=\frac{O D_{550, \text { blank }}-O D_{550}}{O D_{550, \text { blank }}} \times 100
$$

The impact of various parameters on Fucopol's flocculation rate was studied, namely, bioflocculant concentration (0.1$5.0 \mathrm{mg} / \mathrm{L})$, suspended solids content $(1-10 \mathrm{~g} / \mathrm{L})$, flocculation time (0-30 minutes), $\mathrm{pH}$ (3.4-11.6), temperature (5$60^{\circ} \mathrm{C}$ ) and type of cation $\left(\mathrm{NaCl}, \mathrm{KCl}, \mathrm{CaCl}_{2}, \mathrm{MgCl}_{2}, \mathrm{FeCl}_{2}\right.$ and $\mathrm{FeCl}_{3}$ ). The thermal stability of FucoPol was also examined by measuring the FR after subjecting a FucoPol solution $(1 \mathrm{mg} / \mathrm{L})$ to one of the following thermal treatments: (1) overnight freezing at $-80^{\circ} \mathrm{C}$, followed by thawing at room temperature; (2) heating at $80^{\circ} \mathrm{C}$ or $100^{\circ} \mathrm{C}$ for $2 \mathrm{~h}$; (3) autoclaving at $121^{\circ} \mathrm{C}, 1 \mathrm{bar}$, for $20 \mathrm{~min}$. All experiments were conducted with 5 replicas.

The flocculation rate of Enterobacter A47 culture broth and cell-free supernatant were evaluated throughout the cultivation run. Culture broth samples were diluted (1:10, $\mathrm{v} / \mathrm{v})$ with deionized water and centrifuged $(10956 \times \mathrm{g}, 10$ $\min$ ) to obtain the cell-free supernatant samples. For determination of the flocculating activity, $0.1 \mathrm{~mL}$ samples (broth diluted 1:10 (v/v) and the corresponding cell-free supernatant) were added to the kaolin suspension and the FR was determined as described above. The measurements were performed at a temperature of $20^{\circ} \mathrm{C}$.

\subsection{Flocculation mechanism}

Scanning electron microscope was used to observe the surface morphology of FucoPol, as well as the kaolin clay particles and the kaolin clay particles flocculated in the presence of FucoPol. Both type of particles were obtained after centrifuging the suspensions $(3,500 \times 9$, $5 \mathrm{~min})$. The samples were freeze dried and their morphology was assessed through scanning electron microscopy in a Carl Zeiss AURIGA Crossbeam SEM-FIB microscope.

Two different methods, namely transmission optical microscopy and dynamic light scattering (DLS), were used to determine the particle size distribution of the kaolin suspension and the kaolin suspension flocculated with FucoPol. For the transmission optical microscopy analysis, the suspensions $(20 \mu \mathrm{L})$ were spread on microscopy glass plates and observed with an Olympus Provis microscope, at magnification from 2.5 to $20 \times$, at room temperature. Images were acquired with a
Visicam 5.0 VWR. The micrographies, recorded under a bmp format, were calibrated with a certified reticule. DLS analysis was performed at $30^{\circ} \mathrm{C}$ using a Photocor equipment (helium-neon laser, $633 \mathrm{~nm}, 20 \mathrm{~mW}$; $90^{\circ}$ angle) and a B19000 Brookhaven autocorrelator. Analysis were realized using two aliquot samples and performing at least three runs per sample for $1 \mathrm{~min}$. DLS raw data were analysed with Dynals Software (SoftScientific, Israel).

\section{Results and discussion}

\subsection{Bioflocculant characterization}

The bioflocculant used in this study, the extracellular polysaccharide FucoPol, was composed of fucose (35\% mol), glucose $(31 \% \mathrm{~mol})$, galactose $(24 \% \mathrm{~mol})$ and glucuronic acid $(10 \% \mathrm{~mol})$. The acyl group substituents accounted for $12 \mathrm{wt} \%$ of the polymer's mass and comprised pyruvyl, acetyl and succinyl residues. Total protein and inorganic salts contents of $11 \mathrm{wt} \%$ and 7 wt $\%$, respectively, were detected. The polymer had an average molecular weight of $4.4 \times 10^{6} \mathrm{Da}$ and a polydispersity index of 1.9. These FucoPol features, i.e. a high molecular weight macromolecule containing several anionic residues (glucuronic acid monomers and the acyl substituents pyruvyl and succinyl), should support a bioflocculant property [1]. Having a high molecular weight and a high content of hydroxyl and carboxyl groups, namely, uronic acids, are characteristics known to favour the flocculation mechanism [1]. The presence of carboxyl groups, in particular, would allow the molecular chain to stretch as a means of reducing intraand interchain electrostatic repulsion, thus giving rise to a conformation more adapted to promote a multi binding attachment to the kaolin particles $[17,18]$.

The bioflocculant was characterized by FIR spectroscopy (The FTIR spectrum is shown in supplementary material Figure S1). The spectrum showed a broad and intense band at $3327 \mathrm{~cm}^{-1}$ characteristic of the stretching vibrations of the hydroxyl groups $(\mathrm{O}-\mathrm{H})$. This band overlaps with the peak located at $2926 \mathrm{~cm}^{-1}$, which can be assigned to the stretching vibration of the $\mathrm{C}-\mathrm{H}$ of the $\mathrm{CH}_{2}$ groups. The peak at 1722 is due to the $\mathrm{C}=$ $\mathrm{O}$ stretching of carbonyl moieties present in the acyl substituents. The absorption peak observed at $1257 \mathrm{~cm}^{-1}$ is characteristic of the $\mathrm{C}-\mathrm{O}-\mathrm{C}$ vibration of acyls. The band appearing at $1601 \mathrm{~cm}^{-1}$ and the absorption region from 1300 to $1450 \mathrm{~cm}^{-1}$ can be attributed to the asymmetric and symmetric stretching of carboxylates, which are present in the glucuronic acid. The strong adsorption peak at $1016 \mathrm{~cm}^{-1}$ is characteristic of skeletal C-O and $\mathrm{C}-\mathrm{C}$ vibrations of the glycosidic bonds and pyranoid 
ring [13]. FTIR analysis supported that the bioflocculant is a carbohydrate containing acyl groups.

\subsection{Flocculation of kaolin clay suspension with FucoPol}

The flocculating capacity of FucoPol was evaluated by measuring the FR of a kaolin suspension $(5 \mathrm{~g} / \mathrm{L}, \mathrm{W} / \mathrm{v})$ in the presence of $1.0 \mathrm{mg} / \mathrm{L}$ of the polymer. In order to assess the coagulation kinetics and define the optimum flocculation time, samples of kaolin clay suspension (blank) and of kaolin clay in the presence of FucoPol were prepared and allowed to stand for $30 \mathrm{~min}$ (Figure 1). Aliquots were sampled periodically from the upper layer of the test tubes and their optical density $\left(\mathrm{OD}_{550}\right)$ was measured for FR determination. As shown in Figure 2 , after five minutes settling, the decrease in the optical density of the suspension containing FucoPol was considerably lower $(0.33 \pm 0.02)$ than that of the blank ( 1.52 \pm 0.06 ), thus corresponding to an FR of $75 \pm 9.3 \%$. Afterwards, the optical density of the suspension containing FucoPol remained practically unchanged (0.21-0.27), while a gradual decrease was noticed for the blank, reaching a value of $0.35 \pm 0.03$ at $30 \mathrm{~min}$. Accordingly, the FR decreased from $62 \pm 8.9 \%$, for a settling time of $10 \mathrm{~min}$, to $34 \pm 12.4 \%$ after 30 minutes. Due to the difference in kinetics evolution between the optical densities of the flocculated samples and the blank, a standard settling time of 5 min was selected for further testing FucoPol flocculation rate.

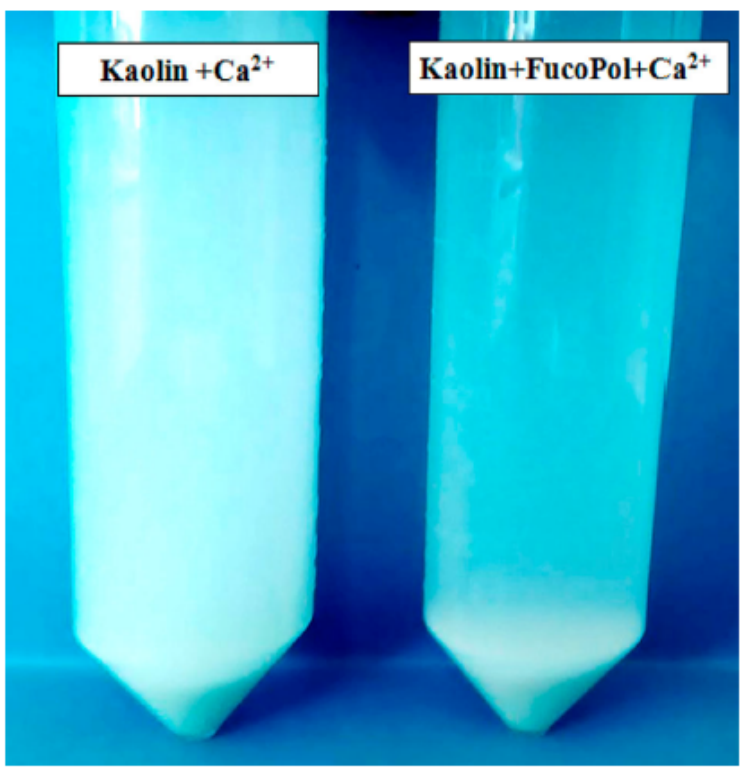

Figure 1. The formation of kaolin particles flocs by the function of FucoPol in presence of $\mathrm{CaCl}_{2}$ after 5 minutes settling.

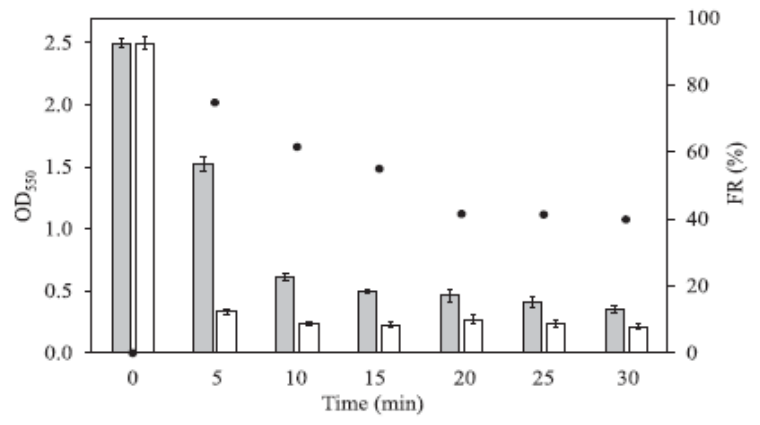

Figure 2. Optical density (measured at $550 \mathrm{~nm}, \mathrm{OD}_{550}$ ) of the upper layer of kaolin clay suspension $(\square$ ) and kaolin clay suspension in the presence of FucoPol at a concentration of $1 \mathrm{mg} / \mathrm{L}$ $(\square)$, for different settling times, and the corresponding FR values (๑).

\subsection{Flocculation performance of FucoPol}

\subsubsection{Effect of bioflocculant dosage}

Figure 3(a) presents the influence of bioflocculant dosage (tested FucoPol concentrations ranged between 0.1 and $5.0 \mathrm{mg} / \mathrm{L}$ ) on the flocculation of kaolin particles. The flocculation rate increased asymptotically as a function of the biopolymer concentration within the concentration range of 0.1 to $1.0 \mathrm{mg} / \mathrm{L}$, to reach a maximum of $74-76 \pm 8.3 \%$. Further increasing the bioflocculant dosage to 2 and $5 \mathrm{mg} / \mathrm{L}$ was not translated into any further improvement of the FR (Figure 3(a)). This dose-effect relationship can be explained by the need to have enough bioflocculant molecules in the mixture to coat the suspended kaolin clay particles and trigger the particles' flocculation [1]. However, excessive bioflocculant dosages may lead to restabilization and change of charge of the colloid solution and reduction of the FR [5]. In fact, a lower FR (28\%) was reported for the flocculation of kaolin clay particles with a FucoPol concentration of $100 \mathrm{mg} / \mathrm{L}$, under similar test conditions [13]. A similar trend was reported by Aljuboori et al. [5] for the flocculation of kaolin particles by addition of the
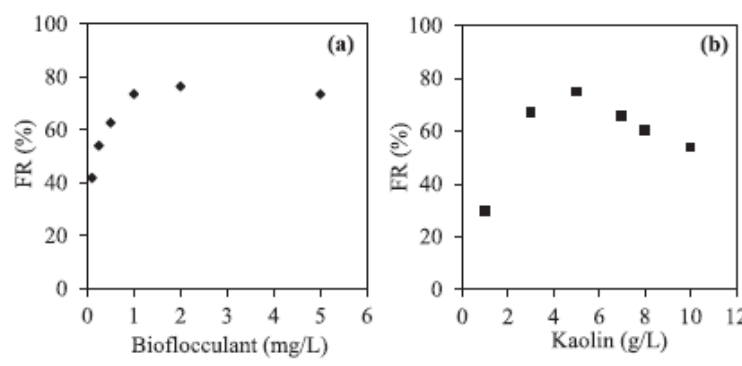

Figure 3. Effect of bioflocculant dosage (a) and suspended solids content (b) on the flocculation rate of kaolin clay suspensions using FucoPol. 
bioflocculant $\mathrm{IH}-7$ produced by Aspergillus flavus, in which reduced FR values were caused by excessive bioflocculant dosage.

The FR values obtained for FucoPol dosages between 1.0 and $5.0 \mathrm{mg} / \mathrm{L}(74-76 \pm 8.3 \%)$ are within the range of values reported by Subramanian et al. [19] for several microorganisms (68-86\%) for bioflocculant dosages between 0.5 and $5.0 \mathrm{~g} / \mathrm{L}$. Considering these results, a FucoPol concentration of $1.0 \mathrm{mg} / \mathrm{L}$ was selected as the optimal dosage for the subsequent flocculation capacity tests.

\subsubsection{Effect of suspended solids content}

The effect of the suspended solids content was evaluated by testing the flocculation of different kaolin suspensions (between 1 and $10 \mathrm{~g} / \mathrm{L}$ ) in the presence of FucoPol at a concentration of $1.0 \mathrm{mg} / \mathrm{L}$ (Figure 3(b)). The maximum FR value $(74 \pm 7.3 \%)$ was reached with $5 \mathrm{~g} / \mathrm{L}$ kaolin clay suspension, a concentration commonly used in flocculation activity studies [10]. Low suspended solids contents (kaolin contents of 1 and $3 \mathrm{~g} / \mathrm{L}$ ) led to low flocculation efficiency ( $F R=30$ and $70 \%$, respectively), which might have been due to an insufficient number of kaolin particles available to form flocs. Above a concentration of $7 \mathrm{~g} / \mathrm{L}$ of solids content, it is worth to notice that the FR also decreased (67-54 $\pm 6.2 \%)$. This observation therefore supports the hypothesis that bioflocculation efficiency is mainly affected by the number of bioflocculant molecules available to coat the kaolin particles and bring them together to form flocs. It can also be anticipated that the kaolin particles concentration in the suspension may also affect interparticle interaction, with a higher particle concentration being less favourable to promote floc formation due to mutual repulsive forces between the kaolin particles. A similar behaviour was reported for the flocculation of a synthetic clay suspension by the polysaccharide produced by Bacillus mojavensis strain 32A [20]. The flocculation efficiency was high ( $F R=90 \%)$ for clay dosages of $1.25-5 \mathrm{~g} / \mathrm{L}$, decreasing to below $70 \%$ as the clay concentration was increased above that value. Also, for the bioflocculant produced by $A$. flavus, constant FR values (>95\%) for kaolin contents in the range $0.5-8.0 \mathrm{~g} / \mathrm{L}$ were reported by Aljuboori et al. [5]. For higher kaolin contents there was a slight decrease of the FR to $86 \%$.

\subsubsection{Effect of $p H$}

As shown in Figure 4(a), the flocculation efficiency of FucoPol was affected by the $\mathrm{pH}$ value of the suspension. Similar FR (70-74\%) were achieved for $\mathrm{pH}$ values between 3.4 and 5.4. These results suggest that FucoPol might be a bioflocculant suitable for use in acidic environments, such as wastewater treatment,
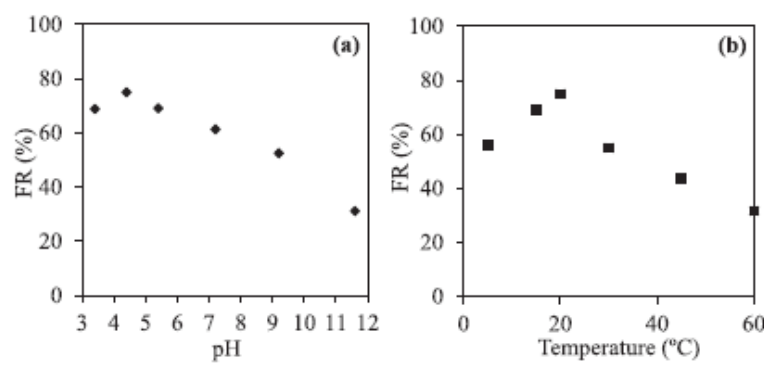

Figure 4. Effect of $\mathrm{pH}$ (a) and temperature (b) on the flocculation rate of kaolin clay suspensions ( $5 \mathrm{~g} / \mathrm{L})$ using FucoPol (1 mg/L) as bioflocculant.

food and mining industries. For $\mathrm{pH} \geq 7.0$, the $\mathrm{FR}$ gradually decreased to values below $60 \%$ (Figure $4(\mathrm{a})$ ). This result is probably due to the evolution of ionization of FucoPol as a function of the $\mathrm{pH}$ value, which is known to affect the flocculation ability of the bioflocculants [21]. At more alkaline $\mathrm{pH}$ values, we should have more negative charges on FucoPol, as well as on kaolin, therefore promoting electric repulsion between the bioflocculant and kaolin particles.

Although some pH-resistant bioflocculants have been reported, such as the one produced by Enterobacter sp. ETH-2 with a high FR (>90\%) in a pH range of 3-9 [22], most of the other flocculation agents are strongly affected by the $\mathrm{pH}$ value of the media. The $\mathrm{pH}$ dependence of FucoPol flocculation activity was similar to that of the polysaccharide secreted by Achromobacter xylosoxidans strain TERI L1 that was effective for flocculation of a kaolin clay suspension over a weakly acidic $\mathrm{pH}$ range (5.5-7.5) [23]. Aljuboori et al. [5] also reported the stability of the bioflocculant $\mathrm{IH}-7$ at a $\mathrm{pH}$ range of 4-8. The bioflocculant produced by Kelbsiella $s p$. ZZ-3 also presented high FR values $(>90 \%)$ between $\mathrm{pH} 3$ and 7 that decreased (61-79\%) for higher $\mathrm{pH}$ values [24]. These variations in the response of these bioflocculants to the $\mathrm{pH}$ value should be linked to the macromolecular features, such as their mean composition, monomer distribution and tertiary structure.

\subsubsection{Effect of temperature}

The FR of FucoPol was also influenced by the temperature. The highest FR values were noticed for temperatures between $15^{\circ} \mathrm{C}$ and $20^{\circ} \mathrm{C}$ (Figure $4(\mathrm{~b})$ ). Outside that range, either for lower $\left(5^{\circ} \mathrm{C}\right)$ or higher temperatures $\left(30-60^{\circ} \mathrm{C}\right)$, the FR values gradually decreased. If an increase in temperature should promote movement and coll ision of the suspended particles, and consequently the formation of flocs, variation in solvation and ionization level with temperature cannot be ruled out. For example, Pan et al. [21] reported the formation of smaller size flocs, with high hydrating capacity, at higher temperatures with a corresponding 
decrease in the flocculation efficiency. Although some authors have reported broad thermal stability of their bioflocculants, such as, for example, the bioflocculant produced by $B$. subtilis DYU1 that maintained a FR above $80 \%$ for temperatures up to $100^{\circ} \mathrm{C}[18]$, in most of the cases, the flocculation ability of biopolymers is influenced by the temperature.

\subsubsection{Thermal stability of the bioflocculant}

The thermal stability of the bioflocculant was evaluated by submitting FucoPol solutions to different thermal treatments: (1) freezing at $-80^{\circ} \mathrm{C}$ for $12 \mathrm{~h}$, followed by thawing at room temperature; (2) heating at $80^{\circ} \mathrm{C}$ and $100^{\circ} \mathrm{C}$ for $2 \mathrm{~h}$; (3) autoclaving at $121^{\circ} \mathrm{C}$, 1 bar, for 20 min. Each solution was then used to flocculate kaolin clay suspensions $(5 \mathrm{~g} / \mathrm{L})$.

Freezing/thawing did not significantly affect the flocculation capability of the biopolymer. After being submitted to that treatment, the biopolymer presented a FR of $72 \pm 4.7 \%$ close to the value obtained for the untreated FucoPol solution (74 $\pm 7.3 \%)$. Similarly, heating the biopolymer's solution at $80^{\circ} \mathrm{C}$ or $100^{\circ} \mathrm{C}$ had no significant impact on FucoPol's flocculation efficiency, as shown by the high FR values obtained (71 $\pm 4.3 \%$ and $71 \pm 3.4 \%$, respectively).

These results demonstrate the thermal stability of FucoPol to temperatures up to $100^{\circ} \mathrm{C}$. Generally, bioflocculants composed mainly of carbohydrates have higher thermal stability, compared to biopolymers made from a peptide backbone that are more susceptible to heat. For example, the polysaccharide bioflocculants synthesized by Enterobacter sp. ETH-2 [22], B. velezensis 40B [25] and Aeromonas sp. [26] were stable after treatments at temperatures up to $100^{\circ} \mathrm{C}$, keeping their flocculation efficiency over $80 \%$. In contrast, the bioflocculant produced by B. subtilis DYU1 [18], mainly composed of polyglutamic acid, had reduced $\mathrm{FR}$ after treatment at $60^{\circ} \mathrm{C}$ and was completely inactivated when heated at $120^{\circ} \mathrm{C}$.

However, upon autoclaving, FucoPol apparently loss its flocculating efficiency, as shown by the considerably lower FR value obtained $(22 \pm 6.2 \%)$. This thermal behaviour might be indicative of an alteration in the conformation of the polysaccharide chain or even a degradation of the bioflocculant [24]. The FR of the bioflocculant produced by Klebsiella sp. ZZ-3 has also shown a decrease of the FR value from $93 \%$ to $53.5 \%$ after being subjected to similar conditions $\left(115^{\circ} \mathrm{C}\right.$, for $\left.20 \mathrm{~min}\right)$ [24].

\subsubsection{Effect of different cations}

The effect of different cations on the flocculation rate of FucoPol was evaluated by using several chloride salts $\left(\mathrm{NaCl}, \mathrm{KCl}, \mathrm{MgCl}_{2}, \mathrm{FeCl}_{2}\right.$ and $\mathrm{FeCl}_{3}$ ) instead of $\mathrm{CaCl}_{2}$ in the FR measurement tests. Lower FR values $(<60 \%)$

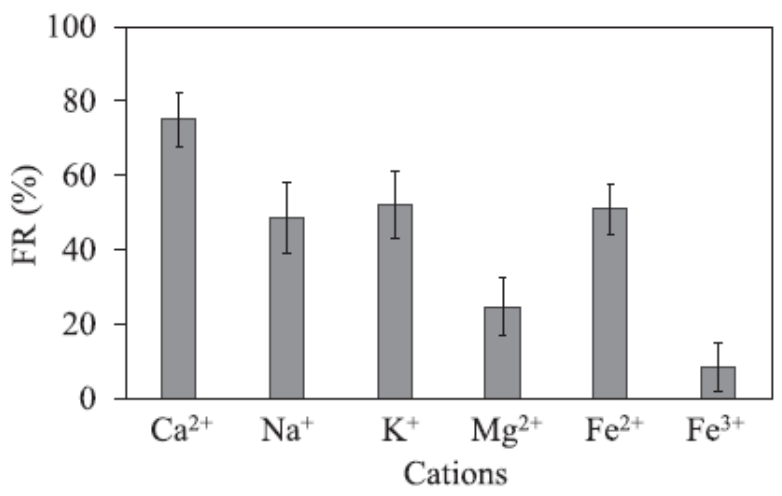

Figure 5. Effect of different cations on the FR of FucoPol.

were obtained in the presence of any of the tested cations, comparing to $\mathrm{CaCl}_{2}$ (74 $\pm 7.3 \%$ ) (Figure 5). Comparable FR values were reached for $\mathrm{Na}^{+}(49 \pm 9.6 \%), \mathrm{K}^{+}$ $(53 \pm 9.1 \%)$ and $\mathrm{Fe}^{2+}(51 \pm 6.8 \%)$. On the other hand, the flocculation efficiency of FucoPol was strongly reduced in the presence of $\mathrm{Mg}^{2+}$ and $\mathrm{Fe}^{3+}(\mathrm{FR}<30 \%)$. Similar results were reported for the bioflocculant produced by the consortium of Halomonas sp. and Micrococcus sp. [27]. The authors disclosed that the highest FR value was obtained for $\mathrm{Ca}^{2+}(72 \%)$, being reduced in the presence of monovalent $\left(\mathrm{Li}^{+}, \mathrm{Na}^{+}\right.$and $\left.\mathrm{K}^{+}\right)$and other divalent $\left(\mathrm{Mg}^{2+}, \mathrm{Mn}^{2+}\right.$ and $\left.\mathrm{Ba}^{2+}\right)$ cations. Also, the flocculation capacity of the bioflocculants produced by several species of the Genera Bacillus, Pseudomonas, Serratia and Yersinia was improved by the presence of $\mathrm{CaCl}_{2}$ [10]. Other cations, such $\mathrm{Li}^{+}, \mathrm{Na}^{+}, \mathrm{K}^{+}, \mathrm{Mg}^{+2}, \mathrm{Al}^{3+}$ and $\mathrm{Fe}^{3+}$, have also been tested in the presence of other bioflocculants $[5,27]$ and, in the most cases, the FR was influenced by the type of cation used. For example, the presence of $\mathrm{Fe}^{3+}$ led to a $40 \%$ decrease of the FR for the polysaccharide secreted by Klebsiella sp. ZZ-3 [24], while that of the bioflocculant produced by Enterobacter sp. ETH-2 was completely lost [22]. The loss or reduction of the flocculation activity in the presence of $\mathrm{Fe}^{3+}$ has been assigned to the higher charge neutralization efficiency of kaolin particles by the cation [24].

\subsection{Flocculation of kaolin clay suspension with culture broth and cell-free supernatant}

The flocculation rate of Enterobacter A47 culture broth and its cell-free supernatant were also evaluated for samples collected at different cultivation times (Table 1). This approach would be of interest since for many applications (e.g. wastewater treatment) there is no need for a bioflocculant with a high purity degree. Hence, the direct use of Enterobacter A47 culture broth or even its cell-free supernatant as bioflocculating agents would result in a less 
Table 1. Flocculation rate of Enterobacter A47 cultivation broth and cell-free supernatant samples collected from the bioreactor during production of FucoPol.

\begin{tabular}{lcclll}
\hline \multirow{2}{*}{$\begin{array}{l}\text { Cultivation } \\
\text { time }(\mathrm{h})\end{array}$} & \multirow{2}{*}{$\begin{array}{c}\text { FucoPol } \\
(\mathrm{g} / \mathrm{L})\end{array}$} & $\begin{array}{c}\text { Bioflocculant } \\
\text { dosage }(\mathrm{mg} / \mathrm{L})\end{array}$ & & \multicolumn{2}{c}{ FR $(\%)$} \\
\hline 0 & 0.16 & 0.03 & 0 & 0 \\
24 & 0.72 & 0.14 & 0 & 0 \\
48 & 2.83 & 0.57 & $24 \pm 5.1$ & $59 \pm 8.0$ \\
72 & 5.00 & 1.00 & $40 \pm 5.2$ & $65 \pm 7.3$ \\
96 & 6.20 & 1.24 & $43 \pm 4.4$ & $76 \pm 8.1$ \\
\hline
\end{tabular}

expensive product application since the procedures for polymer purification would not be necessary.

Due to the high viscosity developed by the broth during cultivation (an apparent viscosity of $910 \mathrm{mPa}$.s was reached after $96 \mathrm{~h}$ of cultivation, measured at $\left.0.82 \mathrm{~s}^{-1}\right)$, the samples had to be diluted for cell removal by centrifugation. In view of this, all samples suffered the same dilution $(1: 10, v / v)$, so the broth samples and the corresponding cell-free supernatant samples would be tested at the same bioflocculant dosage. The results show that both the broth and the supernatant samples demonstrated to possess flocculating activity that increased along the cultivation time (Table 1). Up to $24 \mathrm{~h}$ of cultivation, no flocculating capacity was detected, which demonstrates that the medium had no flocculating capacity and the observed flocculation ability derived from the bacterial products. At $48 \mathrm{~h}$ of cultivation, FR values of $24 \pm 5.1 \%$ and $59 \pm 8.0 \%$ were detected for the broth and the supernatant samples, respectively. The flocculating activity of both type of samples further increased along the cultivation run, reaching maximum values of $43 \pm 4.4 \%$ and $76 \pm 8.1 \%$ respectively, at the end of the experiment (Table 1). The observed increase of the FR was concomitant with the polymer's synthesis and, thus, with the bioflocculant's dosage.

Interestingly, for all cultivation times, the supernatant samples disclosed considerably higher FR values than the broth samples, despite having the same bioflocculant dosage. Actually, the FR of the cell-free supernatant samples was $40-61 \%$ higher than the corresponding broth samples. These results suggest that, for the same total FucoPol concentration in both types of samples, the biopolymer's flocculating ability is significantly affected by the medium, namely the cell content. Due to its biological function, it can be anticipated that FucoPol might remain loosely attached to the cell surface after secretion, thus decreasing its availability to interact with the kaolin particles [28].

The maximum FR obtained for Enterobacter A47 cell-free supernatant, $59-65 \%$, is similar to the values (63-76\%) reported for several studies in which cell-free supernatant samples of several bacteria (e.g. Achromobacter xylosoxidans strain TERI L1 [23], Halobacillus sp. Mvuyo [9], and the consortium of Halomonas sp. Okoh and Micrococcus sp. Leo [27]) were tested as flocculating agents. Higher FR values $(>80 \%$ ) were also reported for the cell-free supernatant of some other microbial bioflocculant producers, including $B$. subtilis [7,18], B. mucilaginosus MBFA9 [17] and Enterobacter sp. ETH-2 [22]. Nonetheless, in most of those reports, considerably higher supernatant dosages (10-100 mL/L) were used for testing the flocculation rate, compared to a dosage of $2 \mathrm{~mL} / \mathrm{L}$ used in the present study.

\subsection{Flocculation mechanism of FucoPol}

\subsubsection{Surface morphology of FucoPol and kaolin flocs}

The surface morphology of dried FucoPol, kaolin clay particles and kaolin clay particles flocculated in the presence of FucoPol was observed under scanning electron microscopy (SEM) (Figure 6). As shown in Figure 6(a), FucoPol exhibits a fibrous structure with interstitial spaces between the ribbon-like fibres network. Figures $6(b, c)$ show the morphology of the kaolin clay particles and the kaolin clay particles flocculated with FucoPol, respectively. It can be observed that the kaolin clay particles were small and homogeneously dispersed, while in the presence of FucoPol, considerably larger flocs were formed. Apparently, the scattered kaolin clay small particles (Figure 6(b)) were connected together into large particles in the presence of FucoPol (Figure 6(c)), therefore highlighting the flocculating performance of the biopolymer for kaolin clay particles.

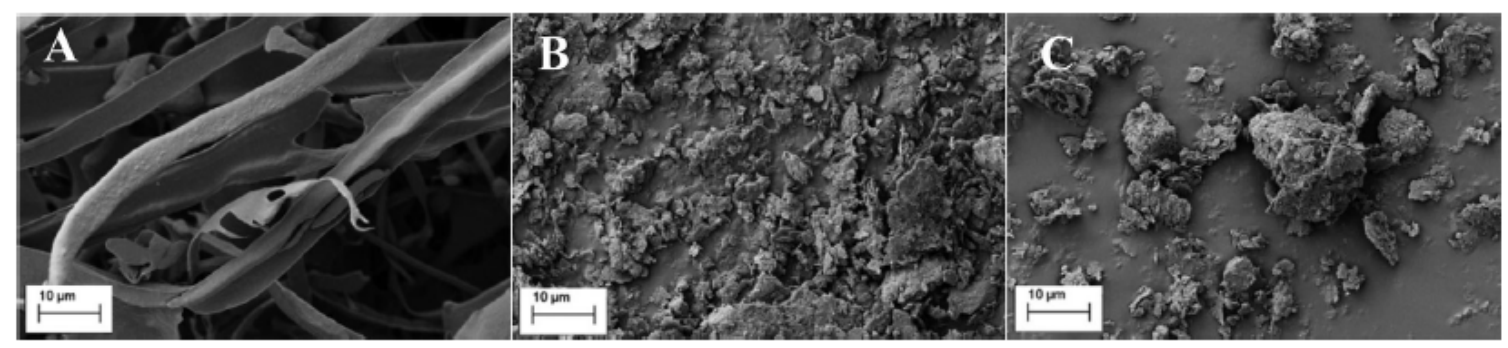

Figure 6. Scanning electron micrograph of (A) purified FucoPol, (B) kaolin clay particles and (C) kaolin clay particles flocculated with purified FucoPol $(1 \mathrm{mg} / \mathrm{L})$. 

The formation of multiaggregates in the presence of FucoPol was also clearly demonstrated by the particle size analysis of the suspensions analyzed by optical microscopy and DLS. Before coagulation, kaolin particles have a mean size around $10 \mu \mathrm{m}$ (mean Id in DLS) but characterized by a larger polydispersity index, with particles in a size range from 5 to $20 \mu \mathrm{m}$ (in some cases up to $50 \mu \mathrm{m}$ ). After FucoPol addition, aggregates are mostly found with a particle size range typically above $20 \mu \mathrm{m}$ up to $75 \mu \mathrm{m}$ (the particle size distribution is shown in supplementary material, Figure S2).

\subsubsection{Flocculation mechanism}

Kaolin particles are negatively charged [5,22]. Since FucoPol is an anionic polysaccharide due to the presence of negatively charged carboxyl groups (i.e. glucuronic acid, pyruvic acid and succinic acid), charge neutralization could not be the main mechanism to describe kaolin particles flocculation by FucoPol. For floc formation, the electrostatic repulsion between the negatively charged kaolin particles must be reduced, which was likely achieved by the presence of $\mathrm{Ca}^{2+}$. Accordingly, the $\mathrm{Ca}^{2+}$-kaolin complexes would interact more easily with the negatively charged carboxyl groups of FucoPol. Due to its high average molecular weight $\left(4.4 \times 10^{6} \mathrm{Da}\right)$, the bioflocculant should be able to bridge particles, leading to the formation of threedimensional flocs able to settle faster than the kaolin particles alone [18].

\section{Conclusions}

FucoPol, an exopolysaccharide produced by Enterobacter A47, demonstrated to efficiently flocculate kaolin suspension. Its high molecular weight, combined with the presence of numerous negative charged residues, rendered FucoPol a good flocculation performance at low dosages. High flocculation effectiveness was demonstrated for wide ranges of $\mathrm{pH}$ and temperatures, and FucoPol was shown to be thermally stable, suggesting its applicability in both cold and hot conditions. Polymer bridging was probably the main mechanism of flocculation considering the nature of the bioflocculant. This study revealed that FucoPol has good potential for colloid aggregation in several applications, such as water treatment, food and mining industries, able to compete with other natural and/or synthetic flocculants.

\section{Acknowledgements}

This work was supported by the Research Unit on Applied Molecular Biosciences, UCIBIO, and by the Materials Research Center, CENIMAT/i3N, which are financed by national funds from FCT/MCTES (UID/Multi/04378/2013, CTM/LA0025/201314 and UID/AGR/04129/2013, respectively) and co-financed by the ERDF under the PT2020 Partnership Agreement (POCl01-0145-FEDER-007728), exploratory project IF/00589/2015 attributed within the $2015 \mathrm{FCT}$ Researcher Program, and grants SFRH/BD/115173/2016 and SFRH/BD/131947/2017. The authors would like to thank Dr. D. Nunes (i3N/CENIMAT, FCTUNL) for her assistance in collecting the SEM images.

\section{Disclosure statement}

No potential conflict of interest was reported by the authors.

\section{Funding}

This work was supported by European Regional Development Fund [grant number POCl-01-0145-FEDER-007728]; Fundação para a Ciência e a Tecnologia [grant number CTM/LA0025/ 2013-14, IF/00589/2015, SFRH/BD/1 15173/2016, SFRH/BD/ 131947/2017, UID/AGR/04129/2013, UID/Multi/04378/2013].

\section{ORCID}

Diana Araújo (1) http://orcid.org/0000-0003-4376-6471 Patrícia Concórdio-Reis (1) http://orcid.org/0000-0001-6143-9170 Ana C. Marques (D) http://orcid.org/0000-0001-6878-1040 Vitor D. Alves (1) http://orcid.org/0000-0002-4117-5582

Elvira Fortunato (D) http://orcid.org/0000-0002-4202-7047

Maria A. M. Reis (D) http://orcid.org/0000-0003-4000-1836

Filomena Freitas (1) http://orcid.org/0000-0002-9430-4640

\section{References}

[1] Salehizadeh H, Yan N. Recent advances in extracellular biopolymer flocculants. Biotechnol Adv. 2014;32 (8):1506-1522.

[2] Giri SS, Harshiny M, Sen SS, et al. Production and characterization of a thermostable bioflocculant from Bacillus subtilis $\mathrm{F} 9$ isolated from wastewater sludge. Ecotoxicol Environ Saf. 2015;121:45-50.

[3] Rudén C. Acrylamide and cancer risk-expert risk assessments and the public debate. Food Chem Toxicol. 2004;42(3):335-349.

[4] Campbell A. The potential role of aluminium in Alzheimer's disease. Nephrol Dial Transplant. 2002;17 (2): 17-20.

[5] Aljuboori AHR, Idris A, Al-joubory HHR, et al. Flocculation behavior and mechanism of bioflocculant produced by Aspergillus flavus. J Environ Manage. 2015;150:466-471.

[6] Peng L, Yang C, Zeng G, et al. Characterization and application of bioflocculant prepared by Rhodococcus erythropolis using sludge and livestock wastewater as cheap culture media. Appl Microbiol Biotechnol. 2014;98 (15):6847-6858.

[7] Sathiyanarayanan G, Kiran GS, Selvin J. Synthesis of silver nanoparticles by polysaccharide bioflocculant produced from marine Bacillus subtilis MSBN17. Colloids Surf B Biointerfaces. 2013;102:13-20.

[8] Zhao C, Zhang Y, Wei X, et al. Production of ultra-high molecular weight poly- $\gamma$-glutamic acid with Bacillus 
licheniformis P-104 and characterization of its flocculation properties. Appl Biochem Biotechnol. 2013;170(3):562-72.

[9] Cosa S, Mabinya LV, Olaniran AO, et al. Production and characterization of bioflocculant produced by Halobacillus sp. Mvuyo isolated from bottom sediment of Algoa Bay. Environ Technol. 2012;33:967-973.

[10] More TT, Yadav JS, Yan S, et al. Extracellular polymeric substances of bacteria and their potential environmental applications. J Environ Manage. 2014;144:1-25.

[11] Yokoi H, Yoshida T, Mori S, et al. Biopolymer flocculant produced by an Enterobacter sp. Biotechnol Lett. 1997;19(6):569-573.

[12] Lu W-Y, Zhang T, Zhang DY, et al. A novel bioflocculant produced by Enterobacter aerogenes and its use in defecating the trona suspension. Biochem Eng J. 2005;27 (1):1-7.

[13] Freitas F, Alves VD, Torres CAV, et al. Fucose-containing exopolysaccharide produced by the newly isolated Enterobacter strain A47 DSM 23139. Carbohydr Polym. 2011;83(1):159-165.

[14] Freitas F, Alves VD, Pais J, et al. Production of a new exopolysaccharide (EPS) by Pseudomonas oleovorans NRRL B-14682 grown on glycerol. Proc Biochem. 2010;45(3):297-305.

[15] Torres CAV, Marques R, Antunes S, et al. Kinetics of production and characterization of the fucose-containing exopolyssacharide from Enterobacter A47. J Biotechnol. 2011;156(4):261-267.

[16] Ferreira ARV, Torres CAV, Freitas F, et al. Biodegradable films produced from the bacterial polysaccharide FucoPol. Int J Biol Macromol. 2014;71:111-116.

[17] Deng SB, Bai RB, Hu XM, et al. Characteristics of a bioflocculant produced by Bacillus muclaginosus and its use in starch wastewater treatment. Appl Microbiol Biotechnol. 2003;60(5):588-593.

[18] Wu J-Y, Ye H-F. Characterization and flocculating properties of an extracellular biopolymer produced from a Bacillus subtilis DYU1 isolate. Proc Biochem. 2007;42 (7):1114-1123.
[19] Subramanian BS, Yan S, Tyagi RD, et al. Extracellular polymeric substances (EPS) producing bacterial strains of municipal wastewater sludge: isolation, molecular identification, EPS characterization and performance for sludge settling and dewatering. Water Res. 2010;44(7):22532266.

[20] Elkady MF, Farag S, Zaki S, et al. Bacillus mojavensis strain 32A, a bioflocculant-producing bacterium isolated from an Egyptian salt production pond. Biores Technol. 2011;102(17):8143-8151.

[21] Pan Y, Shi B, Zhang Y. Research on flocculation property of bioflocculant PG. a21 Ca. Mod Appl Sci. 2009;3 (6):106-112.

[22] Tang W, Song L, Li D, et al. Production, characterization and flocculation mechanism of cation independent, $\mathrm{pH}$ tolerant and thermally stable bioflocculant from Enterobacter sp. ETH-2. PLoS One. 2014;9(12):1-19.

[23] Subudhi S, Bisht V, Batta N, et al. Purification and characterization of exopolysaccharide bioflocculant produced by heavy metal resistant Achromobacter xylosoxidans. Carbohydr Pol. 2016;137:441-451.

[24] Yin YJ, Tian ZM, Tang W, et al. Production and characterization of high efficiency bioflocculant isolated from Klebsiella sp. ZZ-3. Bioresour Technol. 2014;171:336-342.

[25] Zaki SA, Elkady MF, Farag S, et al. Characterization and flocculation properties of a carbohydrate bioflocculant from a newly isolated Bacillus velezensis 40B. J Environ Biol. 2013;34(1):51-58.

[26] Li XM, Yang Q, Huang K, et al. Screening and characterization of a bioflocculant produced by Aeromonas sp. Biomed Environ Sci. 2007;20(4):274-278.

[27] Okaiyeto K, Nwodo UU, Mabinya LV, et al. Characterization of a bioflocculant produced by a consortium of Halomonas sp. and Micrococcus sp. Leo. Int J Environ Res Public Health. 2013;10(10):5097-5110.

[28] Nwodo UU, Green E, Okoh AI. Bacterial exopolysaccharides: functionality and prospects. Int J Mol Sci. 2012;13 (11):14002-14015. 